\title{
The Effect of Primary Health Care Learning Programme in Health Care Service Delivery: Case Study of Ehlanzeni Health District in Mpumalanga Province
}

\author{
Justice. H Ravhura \\ Department of Health Mpumalanga: South Africa \\ humbulanj@gmail.com \\ Nyawo Gumede \\ Tshwane University of Technology, South Africa \\ gumedenb@tut.ac.za \\ Dr Kenneth Dipholo \\ University of Botswana: Botswana \\ dipholok@mopipi.ub.bw
}

Doi:10.5901/jesr.2014.v4n6p207

\section{Abstract}

This research was aimed mainly at determining the significance of the primary health care learning programme in health care service delivery, focusing mainly in the Ehlanzeni Health district of Mpumalanga Province. The focus was on how professional nurses trained in the Primary Health Care programme confidently apply the skills and expertise to the benefit of clients in community health facilities. A quantitative study was conducted at the local clinics of Ehlanzeni Health District. Probability Sampling Technique was used to select 30 Primary Health Care Professional nurses. A questionnaire survey comprising closed ended questions was used to collect data. The data was coded in the computer, analysed in Statistical Analysis software (SAS) packages and summarised using frequency tables. The researcher discovered the value of the training programme as a functional difference in the scope of practise between the Primary Health Care trained and non-trained professional nurses. The interviews distinguished trained professional nurses from general nurses and those specialised in Midwifery and mental health. This clearly indicated that the PHC trained Nurses are capable to render comprehensive health care services in their facilities without causing burden to the referral system. As a result the study strongly recommended that all professional Nurses in Primary health care facilities should be trained in the learning programme in order to strengthen the primary health care system.

Keywords: Primary health care, professional nurses, training programme, Ehlanzeni, Mpumalanga.

\section{Study Orientation}

\subsection{Introduction}

This section provides the background for the study, rationale and an outline of the key elements that are essential for the purpose of the study. The section also concludes with the overview of the community population for the area of study, including the problem statement, which will then lead to objectives of the study and finally the research questions.

\subsection{Background of the Study}

One of the important aspects of ensuring effective and efficient service delivery in the Republic of South Africa is to take services to the people within the public service. This is in line with ensuring that all the legislative frameworks, that is policies and procedures that guide the management of health care services, are implemented in a manner that benefits communities both in rural and urban areas. The services are accessed equally by all community members, regardless of their economic status, background or any other factor that may be a hindrance (WHO, 2009, p.13). 
These services in the Republic of South Africa are rendered through various departments, namely Health, Education, Police services, social development, and women; child and disability services. They are coordinated from National, through Provincial, down to local areas, and services rendered in local areas through Department of Health facilities are no exception to the rule. An important fact to note in the delivery of these services is that Department of Health has the responsibility to ensure that its health workers have quality training and expertise when employed to come into contact with patients and render health related services to the communities.

The South African health sector strategic framework, reiterates the importance of clinical competence by stating that appropriately trained primary health care (PHC) nurses must be available in all public health PHC facilities (DOH, 1999, p.17). These health workers with basic training in general nursing can then study further to specialise in any of the following areas: Psychiatry; Mid-wifery; Primary Health Care and others (Burns \& Grove, 1993, p.7). The nurses have the opportunity according to the health policy document formulated in 1996 for the country's primary health care services, to be a specialised group, traditionally known as primary health care trained professional nurses, and are therefore expected to function independently within these public health care facilities (Magobe et al, 2014, p.3). A training programme for these nurses has been in place since 1996 and is offered by the University of Pretoria and South Africa Health Military Services, to ensure these competencies are properly developed, and the country has Professional Nurses who are able to manage primary health care facilities and render quality medical care services to communities without an in-house medical doctor.

After completing the learning programme, trained nurses are anticipated to put into practice the critical skills, knowledge, and competencies they acquired through learning. 'On completion of the programme learners/ professional nurses should be able to function independently (as clinical nurse practitioner) with more limited referral to a medical practitioner in public Primary Health Care facilities' (Beukes, 1983; DOH 2001b:23)

\subsection{Geographic Background}

Mpumalanga Province constitutes of three districts: Ehlanzeni, Gert Sibande and Nkangala region, which are part of the overview structure of the management of its structure. Ehlanzeni district is situated in the south eastern part of Mpumalanga Province next to Mozambique boarder in the east and Swaziland border in the south.

Ehlanzeni district is the biggest of the three districts of Mpumalanga Province with an estimated population of 1593222 (ANON, 2012, p.15).The district constitutes of five local municipalities or rather sub-districts, and they are Bushbuckridge, Mbombela, Umjindi, Thabachweu and Nkomazi, as they are indicated in the outlined map on Figure 1.1 below. Ehlanzeni is mostly comprised of areas which are declared nodal (deepest rural) areas.

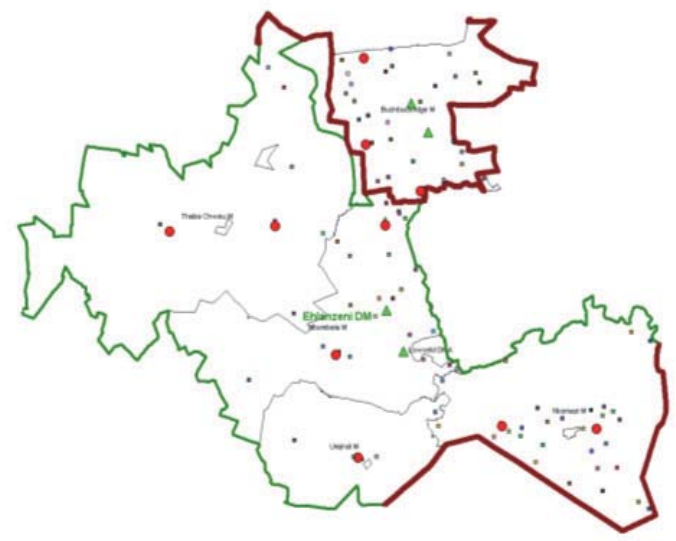

Figure 1: The Ehlanzeni District (Source: Anon, 2012).

The district has 13 hospitals (8 district hospitals, 2TB specialised hospitals, 2 regional hospitals and 1 tertiary hospital) and 121 Primary Health care facilities (18community health centres and 103 clinics) rendering health care to the communities in the local areas of Ehlanzeni (ANON, 2012, p.23). Some of the Primary Health Care facilities operate for 
24 hours whereas some operate for 8 hours, seven days a week. These clinics and community health centres do not have fulltime doctors stationed in the facilities permanently, but rely primarily on doctors in hospitals.

Nonetheless, Doctors' visits to the Primary Health Care facilities are unpredictable, as they are determined by the workload in the hospitals. Thus, most of the time the Primary Health Care have to manage the cases in the community through from history taking; assessments; diagnoses; prescription and referral where relevant. In addition to rendering health care services, nurses also have related responsibilities within the work component to huge communities in the local areas of Ehlanzeni as reflected in the Table 1. below according to the sub-districts as mentioned already.

Table 1: Ehlanzeni population (Source: Anon, 2012).

\begin{tabular}{|l|c|c|c|c|c|c|}
\cline { 2 - 7 } \multicolumn{1}{c|}{} & \multicolumn{4}{c|}{ Population } \\
\cline { 2 - 7 } \multicolumn{1}{c|}{ Name Sub-District } & Total Population & \% Uninsured & $\begin{array}{c}\text { Uninsured } \\
\text { Population }\end{array}$ & $\begin{array}{c}\text { Total } \\
\text { Population }\end{array}$ & \% Uninsured & $\begin{array}{c}\text { Uninsured } \\
\text { Population }\end{array}$ \\
\hline Bushbuckridge & 608,851 & $89 \%$ & 541,877 & 603884 & $89 \%$ & 537457 \\
\hline Mbombela & 489,696 & $89 \%$ & 435,829 & 484684 & $89 \%$ & 431369 \\
\hline Nkomazi & 337,208 & $89 \%$ & 300,115 & 334642 & $89 \%$ & 297831 \\
\hline ThabaChweu & 85,825 & $89 \%$ & 76,384 & 84697 & $89 \%$ & 75380 \\
\hline Umjindi & 56,707 & $89 \%$ & 50,469 & 55937 & $89 \%$ & 49784 \\
\hline Ehlanzeni & $1,578,287$ & $89 \%$ & $1,404,675$ & $1,563,844$ & $89 \%$ & 1,391821 \\
\hline
\end{tabular}

Table 1 above shows that the local areas of Ehlanzeni have a total population of over 1.5 million. This means that there is a huge demand for primary health care services, not to mention the added burden resulting from the HIVIAIDS pandemic hence the dire need for skilled primary health care professionals. It is important to note that earlier projections on HIV prevalence in the 1990s, was that it would not exceed $25.0 \%$, but later shown that in most African states, including the Republic of South Africa, the prevalence has reached levels above 38.6\% (Whiteside et al, 2003, p.14). This shows excessive demand for primary health care services hence the need to capacitate them with trained professionals.

\subsection{Problem Statement}

Primary Health Care facilities are the first contact point of health care services to the community. As such it is crucial that the services they provide are as good as those provided in hospitals to ensure parity in the quality of services hence reduce referrals and overcrowding at hospitals. Therefore nurses at the Community health centres and clinics ought to be well equipped with skills, knowledge and competency to provide quality health care services. This is the reason why training of Primary Health Care nurses is very imperative so that they can be imparted with necessary skills and critical competencies.

In the district office, the Human Resource Development unit is responsible for the training of Primary Health Care nurses although the execution of such training programme depends on the availability of funds from the Provincial Office. The Primary Health Care training programme focuses on improving health care services through imparting nurses with necessary skills, competencies and knowledge. The standard number of Primary Health Care trained nurses is 2 Professional Nurses in Community Health Centres (operating for 24 hours) and one professional nurse in clinics operating for 8 hours. The South African Health Sector Strategic Framework of 1999-2004 reiterates that the importance of clinical competencies by stating that appropriately trained PHC nurses must be available in all public PHC facilities (DOH, 1999, p.17). Thus nurses should be able to asses, diagnose, treat and prescribe in the facilities.

Currently, there are complaints about the health care services rendered by professionals in health facilities especially in Community health centres and clinics. This research sought to evaluate the effectiveness of the primary health care learning programme, through investigating how the professional nurses render health care services in community health centres and clinics within Mpumalanga Province.

\subsection{Research Objectives}

Burns \& Grove (1993, p.211) states that research objectives are clear, concise, declarative statements that are to be of the effectiveness of the Primary Health Care learning programme (trained professional nurses), on health care service 
delivery in the clinics and community health centres, within Ehlanzeni district.

The specific objectives of this study are:

- Determine the relationship between the primary health care learning programme and the health care service delivery, and how they are effectively applied to benefit clients in community facilities.

- To determine the difference between in the quality of services provided in facilities with primary health care trained nurses and those without primary health care training.

- To examine whether primary health care training programme is effective in addressing the challenge of lack medical doctors in clinics and community health centres.

\section{Literature Review}

\subsection{Introduction}

The review of literature is intended to help the researcher "to gain in-depth knowledge needed to make changes in practise or to study a selected problem" (Burns \& Grove, 1993, p.141) and to ascertain whether the research findings are ready for use in practice, as a build on and/or comparison with previous research. In seeking to discover how the primary health care training programme is impacting on service delivery, it is important to then look objectively on the history that led to the formation of the training. But, before embarking on the process of unpacking this concept and its origins it is important to have an understanding of these terminologies.

\subsection{Definitions}

1. Primary Health Care- the first contact point of health care service to the community. Alma Ata conference (1978) has defined Primary Health Care as Primary Health Care based on practical, scientifically sound and social acceptable methods and technology made universally accessible to individuals and families in the community and country can afford to maintain at every stage of their development in the spirit of self-reliance and self-determination. It forms an integral part both of the country and health system, of which it is the central function and main focus and the overall social and economic development of the community. It is the first level of content of individuals and the family with the national health system bringing health care as close as possible to where people live and work and constitutes the first element of continuing.

2. Primary Health Care learning programme- Clinical nursing, diagnosis, treatment and care package...A programme aimed at equipping nurses with clinical knowledge, skills and abilities, essential for patient assessment; diagnoses; treatment and care and incorporates clinical competencies of prescribing and issuing essential drug included in the PHC essential drug list (schedule 1-4 drugs only) (DOH, 1996, p.17).

3. Health Care Service- comprehensive delivery of health care service in a specified geographic area. The National Health Act (No.61 of 2003), in section 30 (2) which relates to the district health system, states that service rendered must have due regard to the principle laid down in the Constitution of South Africa (section 27 and 195) as well as inter alia, quality, effectiveness and efficiency.

\subsection{The PHC Learning Programme}

The research will then look at how it (Primary Health Care Programme) is benefiting comprehensive health service delivery in institutions and how it impacts on multidisciplinary approach in the levels of care within health. Then further analyse how the training shapes the professional conduct, because as Magobe et al $(2010$, p.3) states that the professional nurses execute this clinical functions with the competencies, being equipped with clinical knowledge; which includes prescription of drugs in the Primary Health care setting. A PHC learning programme aims at equipping nurses with clinical knowledge, skills and abilities, essential for patient assessment; diagnoses; treatment and care in primary health care facilities (DOH, 2000). PHC is at the district level where many responsibilities are taken and put into operational action, from the central government by the health workers. This is supported by the model hereunder in Figure 2 that shows the importance of professional development. 


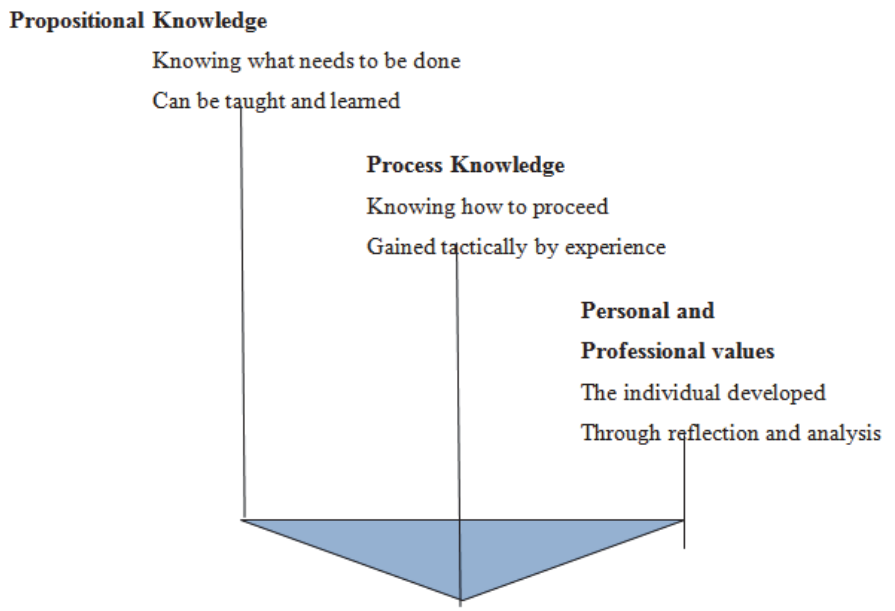

Figure 2: The personal and professional development of a Health worker. (Adapted from: Boom et al, 2006.)

Figure 2 above shows the benefit of professional development to clients and health workers in terms of improving knowledge, skills, and attributes (Boom et al, 2006, p.6). Critical and essential services are required to best meet the health needs of the nation, hence the need for professional development of primary health care nurses (ANON, 1001, P.7).

This is emphasized by ANON (2012, p.7-49) by stating that "district health systems help to implement the primary health care approach in the best possible manner, as it makes it to be part of the provincial and national health systems, ideally connected to the other, as it is best conducive to consolidation and coordination of health care services and resources". It is on the basis of this proposition that primary health care professional nurses should be adequately trained since they are close to the communities.

Before rolling out the PHC Learning Programme, it was piloted at the University of Limpopo. The pilot project used both residential and decentralised modules. The pilot project revealed that the training programme is based on the principles of problem based learning and community based learning and patient-centred care approach. It further revealed the trainee satisfaction ascribed to the community based visits, classroom lectures and dissatisfaction with onsite supervision and training materials.

The pilot project further noted that the administration of public health systems involves various resource components hence the need for decentralised control of resources for efficient control of personnel, budgeting, with direct impact on responsibility of accountability of primary health care facilities administration. Thus, decentralized administration of public health system promotes the bottom-up approach.

\section{Research Methods and Procedures}

\subsection{Research Design}

Research design is a plan according to which we obtain research participants and collect information from them. "A research design articulates a clear programme of action that shows the research design path, sampling procedures and strategies, methods of data collection, data collection procedures and data collection instruments and analysis strategies"(Leedy\&Ormrod, 2010).

The study mainly employed a quantitative design which is an exploratory, descriptive and contextual research method (Burns \& Grove, 1993, p.347 and Monton, 1996, p.103). Quasi- experimental type of quantitative research was also used to examine cause-and -effect relationships between the Primary Health Care Learning Programme and health care service delivery. Quantitative methodology dealt with analytical research data whereas qualitative explanatory design explored the experiences and positions of the respondents sample population. Quantitative methodology is associated with analytical research and its purpose is to arrive at a universal statement while qualitative methodology deals with subjective data that are produced from the minds of the respondents or interviews, is presented by the 
language instead of numbers (Welman et al, 2005).

\subsection{Target Population}

Data were collected by conducting semi-structured interviews with the key informants, who are professional nurses trained in primary health care and working in community health centres and clinics that are without doctors. The interviews were supplemented by the questionnaire self-assessment survey. The participants were at first randomly selected and those not trained in primary health care were eliminated from the sample. The questionnaire served as reliable and relevant tool used to obtain requisite data. This is emphasized by Burns \& Grove (1993, p.368) who states that a questionnaire is a printed self-report form designed to elicit information that can be obtained through written responses of the subject.

\subsection{Sampling Strategy}

Sampling involves selecting a group of people, events, behaviours, or other elements with which to conduct a study (Burns \& Grove, 1993, p.235). This focused on the Primary Health Care facilities, which include community health centres and clinics. The variable for the inclusion of the sample is whether the randomly selected participant is a professional nurse trained in primary health care or not. In this study Probability Sampling method whereby all members of the population has an equal chance of being selected for the sample was used in order to select the participants (Leedy \& Ormrod, 2010).

\subsubsection{Random Sampling method}

The random sampling in this research personifies each individual within the professional nursing population having an equal opportunity to be selected for the sample, which then simply means that all the selected, are initially given an equal opportunity to participate in the study. Selected individuals were further probed in terms of training achieved beyond basic general nursing training, which is the determinant of accurate responses that reflect and impact on the objectives of the research. Thus, the sample was split in two, first were the primary participants wherein the random sampling method is more evident, then the second categorisation was based on secondary participants who were professional nurses trained in primary health care and thirty were randomly selected to participate in the study.

The 30 participants where from three sub districts out of the five sub districts in the district of Ehlanzeni, were the focus was narrowed to one community health centre and two clinics per sub district namely:

1. Mbombela sub district were the participants were from Nelspruit community health centre, Kanyamazane clinic and Zwelisha clinic.

2. Umjindi sub district were the participants were from Thekwane community health centre, Lowcreek clinic and Ma'Africa clinic.

3. Bushbuckridge sub district were the participants were from Dwarsloop community health centre, Maviljan clinic and Marite clinic.

\subsection{Data Collection}

Data was collected by means of questionnaire survey. The questionnaire consisted of closed ended questions based mainly on a Five Point Likert Scale" (Leedy \& Ormrod, 2010) and a few open-ended questions.

The process of gaining access to the health facilities for interviews was through a permit obtained from the authorities. Table 2 below provides information on respondents by health facility. 
Table 2: Respondents by health facility

\begin{tabular}{|c|c|c|c|c|}
\hline Sub district & Primary health care Facility & Interviewee (Gender) & Years of Experience & Type of Training \\
\hline \multirow{8}{*}{$\begin{array}{l}\text { Mbombela } \\
6 \text { PHC Trained }\end{array}$} & \multirow{4}{*}{ Nelspruit $\mathrm{CHC}$} & Female & 5 years & PHC trained \\
\hline & & & & \\
\hline & & Female & 10 years & PHC Trained \\
\hline & & & & PHC Trained \\
\hline & \multirow{2}{*}{ Kanyamazane clinic } & Female & 12 years & PHC Trained \\
\hline & & Female & 6 years & PHC Trained \\
\hline & \multirow{2}{*}{ Zwelisha clinic } & Female & 5 years & PHC trained \\
\hline & & Male & 10 years & PHC Trained \\
\hline & Thekwane $\mathrm{CHC}$ & Female & 9 Years & PHC Trained \\
\hline & & Female & 6 Years & PHC Trained \\
\hline \multirow{7}{*}{$\begin{array}{l}\text { Umjindi } \\
5 \text { PHC Trained }\end{array}$} & \multirow{2}{*}{ Brondal Clinic } & & & \\
\hline & & Female & 7 years & PHC trained \\
\hline & \multirow{2}{*}{ Lowcreek clinic } & Female & 7 years & PHC Trained \\
\hline & & Female & 9 years & PHC trained \\
\hline & \multirow{3}{*}{ Ma'Africa clinic } & Female & 8 years & PHC trained \\
\hline & & Female & 8 years & PHC Trained \\
\hline & & & & PHC Trained \\
\hline \multirow{10}{*}{$\begin{array}{l}\text { Bushbuckridge } \\
7 \text { PHC Trained }\end{array}$} & \multirow{2}{*}{ Dwarsloop CHC } & Female & 1 year & PHC trained \\
\hline & & Male & 5 years & PHC Trained \\
\hline & Maviljan clinic & Male & 5 years & PHC Trained \\
\hline & Arthurseat clinic & Male & 9 years & PHC Trained \\
\hline & \multirow{2}{*}{ Marite clinic } & Female & 4 years & PHC trained \\
\hline & & Male & 6 years & PHC Trained \\
\hline & \multirow{2}{*}{ Thulamahashe $\mathrm{CHC}$} & Female & 5 Years & PHC Trained \\
\hline & & Male & & PHC Trained \\
\hline & \multirow[b]{2}{*}{ Agincourt $\mathrm{CHC}$} & Female & 5 years & PHC Trained \\
\hline & & Male & & PHC trained \\
\hline \multirow[t]{4}{*}{$\begin{array}{l}\text { Nkomazi } \\
7 \text { PHC Trained }\end{array}$} & Block C clinic & $\begin{array}{c}\text { Male } \\
\text { Female }\end{array}$ & 12 Years & $\begin{array}{l}\text { PHC Trained } \\
\text { PHC Trained }\end{array}$ \\
\hline & $\begin{array}{l}\text { Naas CHC } \\
\text { Mangweni clinic }\end{array}$ & $\begin{array}{l}\text { Female } \\
\text { Female }\end{array}$ & 5 years & $\begin{array}{l}\text { PHC Trained } \\
\text { PHC Trained }\end{array}$ \\
\hline & $\begin{array}{l}\text { Jeeps Reef Clinic } \\
\text { Steenbook Clinic }\end{array}$ & $\begin{array}{l}\text { Female } \\
\text { Female }\end{array}$ & $\begin{array}{l}5 \text { Years } \\
13 \text { Years }\end{array}$ & $\begin{array}{l}\text { PHC Trained } \\
\text { PHC Trained }\end{array}$ \\
\hline & Schoemansdal Clinic & Female & 5 Years & PHC Trained \\
\hline \multirow[t]{3}{*}{$\begin{array}{l}\text { Thabachweu } \\
5 \text { PHC Trained }\end{array}$} & Mashishing Clinic & $\begin{array}{l}\text { Female } \\
\text { Female }\end{array}$ & $\begin{array}{l}11 \text { Years } \\
14 \text { Years }\end{array}$ & $\begin{array}{l}\text { PHC Trained } \\
\text { PHC Trained }\end{array}$ \\
\hline & Lydenburg Clinic & $\begin{array}{l}\text { Female } \\
\text { Female }\end{array}$ & 6 Years & $\begin{array}{l}\text { PHC Trained } \\
\text { PHC Trained }\end{array}$ \\
\hline & Sabie Clinic & Female & 5 Years & PHC Trained \\
\hline
\end{tabular}

\subsection{Data Analysis}

Data was coded, analysed in Statistical Analysis software (SAS) packages and summarised using frequency tables. Whereas quantitative data was subjected to deductive analysis, qualitative data was analysed inductively and textually" (Leedy \& Ormrod, 2010) 


\section{Research Findings}

\subsection{Results of the Study}

\subsection{Introduction}

This chapter presents the results of the study in terms of demographic information, and opinions of respondents on the significance of the Primary Health Care Learning Programme on health care service delivery at Ehlanzeni District in Mpumalanga Province.

As stated in the previous chapter, data was analysed using the Frequency Procedures in the Statistical Packages for Social Sciences (SPSS) Version 21. This procedure treated data as categorical count data to obtain simple frequencies of occurrence as well as simple proportions.

A total of $n=30$ respondents, out of the original sample size of $n=30$, voluntarily completed the questionnaires through a face-to-face personal interviews. It should be noted that all $30 \mathrm{I}$ respondents were available to participate for the entire duration of the study and this represented a $100 \%$ response rate. The results are presented in terms of demographics information, followed by opinions of respondents as well as cross tabulations on the significance of the Primary Health Care Learning Programme on health care service delivery at Ehlanzeni District in Mpumalanga Province.

\subsection{Demographic Information}

The profile of the respondents was analysed in terms of gender, age, job experience and profession. The results are presented below as simple frequency of occurrences and simple proportions, as well as in graphic displays.

\subsubsection{Profile of respondents by gender}

Table 4.1 and Figure 4.1 present the profile of respondents by gender. The results indicate that $73.33 \%$ of respondents were females, while $26.67 \%$ were males. In other words, the majority of respondents were females.

Table 4.1: Profile of respondents by gender

$\begin{array}{ccccc}\text { Gender } & \text { Frequency } & \text { Percent } & \text { Cumulative Frequency } & \text { Cumulative Percent } \\ \text { Female } & 22 & 73.33 & 22 & 73.33 \\ \text { Male } & 8 & 26.67 & 30 & 100.00\end{array}$

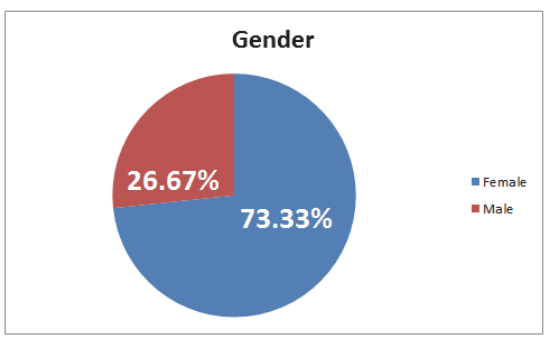

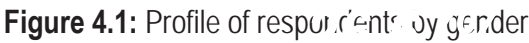

\subsubsection{Profile of respondents by age category}

Table 4.2 and Figure 4.1 present the profile of respondents by age category. The results indicate that $30 \%$ of respondents were 30 years and younger, $50 \%$ of respondents were between the ages 30 to 40 years of age, $18.60 \%$ of respondents were between 35 to 44 years of age, and another $20 \%$ of respondents were between 41 to 50 years. Most of the respondents (50\%) were below 40 years; there is an opportunity for the younger generation to be capacitated on the Primary Health Care Learning Programme. 
Table 4.2: Profile of respondents by age

$\begin{array}{ccccc}\text { Age } & \text { Frequency } & \text { Percent } & \text { Cumulative Frequency } & \text { Cumulative Percent } \\ \mathbf{1} & 9 & 30.00 & 9 & 30.00 \\ \mathbf{2} & 15 & 50.00 & 24 & 80.00 \\ \mathbf{3} & 6 & 20.00 & 30 & 100.00\end{array}$

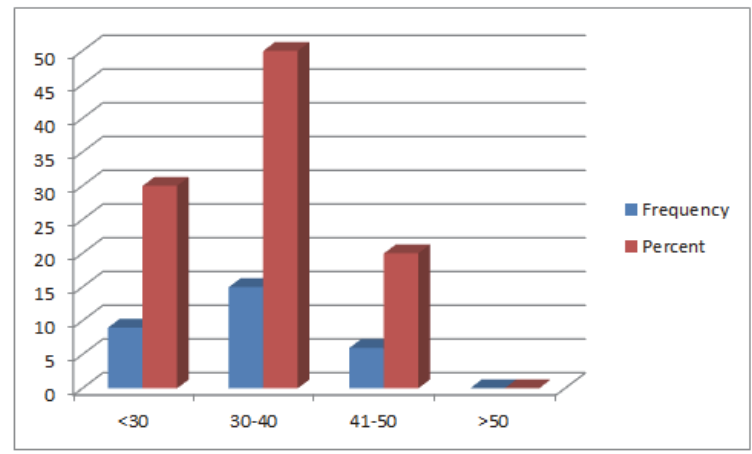

Figure 4.2: Profile of respondents by age category

\subsubsection{Profile of respondents by Profession}

Table 4.4 and Figure 4.2 present the profile of respondents by profession. The results indicate that $100 \%$ of respondents were Professional nurses who were trained in Primary Health Care Learning Programme.

Table.4.3: Profile of respondents by Profession

$\begin{array}{ccccc}\text { Profession } & \text { Frequency } & \text { Percent } & \text { Cumulative Frequency } & \text { Cumulative Percent } \\ 1 & 30 & 100.00 & 30 & 100.00\end{array}$

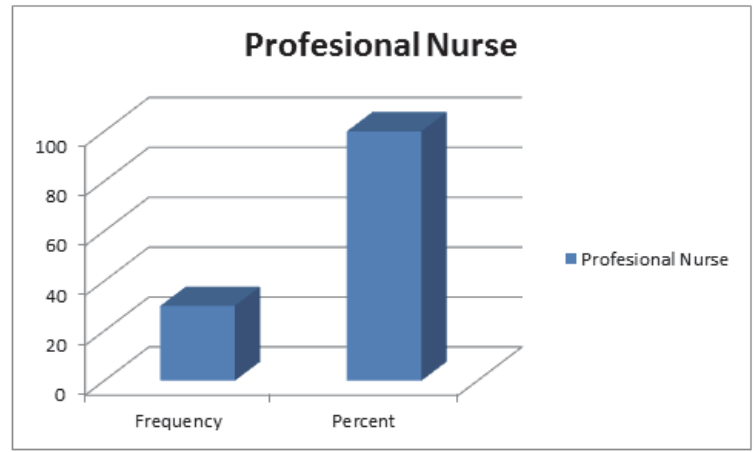

Figure 4.3: Profile of respondents by Profession.

\subsubsection{Profile of respondents by Job Experience}

The results in Table 4.6 and Figure 4.3 indicate that $30 \%$ of respondents had more than 5 years of job experience and $50 \%$ of respondents had 5 to 10 years of job experience. Only $6 \%$ of respondents had a job experience of between 11 to 15 years. None of the respondents had more than 15 years of job experience. 
Table 4.4: Profile of respondents by Job Experience

\begin{tabular}{|c|c|c|c|c|}
\hline $\begin{array}{c}\text { Experience } \\
1 \\
2 \\
3\end{array}$ & $\begin{array}{c}\text { Frequency } \\
9 \\
15 \\
6\end{array}$ & $\begin{array}{c}\text { Percent } \\
30.00 \\
50.00 \\
20.00\end{array}$ & $\begin{array}{c}\text { Cumulative Freque } \\
9 \\
24 \\
30\end{array}$ & \\
\hline & $\begin{array}{r}50 \\
45 \\
40 \\
35 \\
30 \\
25 \\
20 \\
15 \\
10 \\
5 \\
0\end{array}$ & $.5-1$ & $\underset{>15}{\longrightarrow}$ & $\begin{array}{l}\text { - Frequency } \\
\text { - Percent }\end{array}$ \\
\hline
\end{tabular}

\section{Cumulative Percent \\ 30.00 \\ 80.00 \\ 100.00}

Figure 4.4 Profile of respondents by Job Experience

\subsection{Opinion Related Responses}

Respondents were asked a series of closed-ended questions on their opinions with regard to Primary Health Care Learning Programme. The sub-sections below present the results of the analysis in terms of simple frequencies and proportions for the following themes: Critical clinical competencies and Administrative competence.

\subsubsection{Phc Learning Programme- Clinical Competence \& Administrative Competencies}

The ratings were based on 4 Point Likert scales with the following ratings: (1) strongly disagree, (2) Disagree, (3) Neither Agree Nor Disagree, (4) Agree, and (5) Strongly Agree. The results are presented in Table 4.10 for a set of variables.

Table: 4.5: Responses on questions related to Clinical Competence

\begin{tabular}{|c|c|c|c|c|c|}
\hline \multicolumn{6}{|c|}{$\begin{array}{c}\text { B.1 PHC Learning Programme-Clinical Competence } \\
\text { Responses in percentage } \%\end{array}$} \\
\hline & $\begin{array}{l}\text { Strongly } \\
\text { Agree (5) }\end{array}$ & $\begin{array}{c}\text { Agree } \\
(4)\end{array}$ & $\begin{array}{l}\text { Neither Agree Nor } \\
\text { Disagree (3) }\end{array}$ & $\begin{array}{c}\text { Disagree } \\
(2)\end{array}$ & \begin{tabular}{|c|} 
Strongly \\
Disagree (1)
\end{tabular} \\
\hline 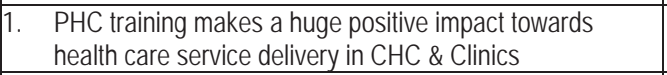 & $86.67 \%$ & $13.33 \%$ & 0 & 0 & 0 \\
\hline $\begin{array}{|ll|}2 . & \text { PHC trained Professional Nurses work independently } \\
\text { without direct supervision of the doctor }\end{array}$ & $86.67 \%$ & $6.67 \%$ & $6.67 \%$ & 0 & 0 \\
\hline $\begin{array}{ll}\text { 3. } & \text { PHC trained Professional nurses can assess, diagnose, } \\
\text { treat and prescribe for patients }\end{array}$ & $100 \%$ & 0 & 0 & 0 & 0 \\
\hline \begin{tabular}{|l} 
4. \\
$\begin{array}{l}\text { PHC training programme_ensures early diagnosis of } \\
\text { diseases by proper screening }\end{array}$
\end{tabular} & $60 \%$ & $33.33 \%$ & $6.67 \%$ & 0 & 0 \\
\hline \begin{tabular}{ll|} 
5. & PHC training programme contribute towards reducing the \\
referral of patients to the hospital
\end{tabular} & $83.3 \%$ & $16.67 \%$ & 0 & 0 & 0 \\
\hline 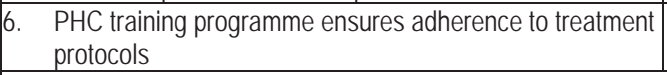 & $50 \%$ & $50 \%$ & 0 & 0 & 0 \\
\hline \multicolumn{6}{|c|}{ B.2 PHC Learning Programme-Administrative Competence } \\
\hline $\begin{array}{|ll|}\text { 7. } & \text { PHC training programme contributes to reducing patient } \\
& \text { waiting time for services in CHC's \& clinics } \\
\end{array}$ & $26.67 \%$ & $66.67 \%$ & $6.67 \%$ & 0 & 0 \\
\hline \begin{tabular}{|l} 
8. \\
PHC training programme_ensures rendering of \\
comprehensive quality health care programs
\end{tabular} & $43.33 \%$ & $56.67 \%$ & 0 & 0 & 0 \\
\hline $\begin{array}{|ll|}\text { 9. } & \text { PHC training programme_improves professional nurse's } \\
\text { skills in facility management, report writing and monitoring }\end{array}$ & $66.67 \%$ & $33.33 \%$ & 0 & 0 & 0 \\
\hline $\begin{array}{l}\text { 10. PHC training programme is key in prevention of ill-health, } \\
\text { promotion of better health through primary health education }\end{array}$ & $66.67 \%$ & $20 \%$ & $13.3 \%$ & 0 & 0 \\
\hline
\end{tabular}


In the sub-sections below, data was treated as a categorical variable to obtain simple frequencies for each question presented separately. Discussions were categorized into two major themes: clinical competencies and administrative competency

Table 4.6: Effect of PHC training programme

\begin{tabular}{|ccccc|}
\hline Q1 & Frequency & Percent & Cumulative Frequency & Cumulative Percent \\
$\mathbf{4}$ & 4 & 13.33 & 4 & 13.33 \\
$\mathbf{5}$ & 26 & 86.67 & 30 & 100.00 \\
\hline
\end{tabular}

Table 4.6 above reflects the results of the opinion that the PHC training programme makes a huge positive impact towards health care services delivery in clinics. $86.67 \%$ of respondents strongly agreed that PHC training programmes makes huge positive impacts on health care service delivery in clinics. $13.33 \%$ of respondents agreed that the training programme makes a huge positive impact on health care service delivery.

Table 4.7: Accountability and Responsibility

\begin{tabular}{|ccccc|}
\hline Q2 & Frequency & Percent & Cumulative Frequency & Cumulative Percent \\
$\mathbf{3}$ & 2 & 6.67 & 2 & 6.67 \\
$\mathbf{4}$ & 2 & 6.67 & 4 & 13.33 \\
$\mathbf{5}$ & 26 & 86.67 & 30 & 100.00 \\
\hline
\end{tabular}

Table 4.7 above displays the results of the opinion of trained PHC professional nurses working independently without the supervision of the doctor. $86.67 \%$ of respondents strongly agreed that the trained PHC trained professional nurses can work independently without doctor's supervision. 6.67\% agreed that PHC trained professional nurses can work independently without the supervision of the doctor. $6.67 \%$ of respondents neither agreed nor disagreed. Majority of the respondents strongly agreed that the trained professional nurses can work independently without the supervision of the doctor.

Table 4.8: Critical competency and knowledge

$\begin{array}{ccccc}\text { Q3 } & \text { Frequency } & \text { Percent } & \text { Cumulative Frequency } & \text { Cumulative Percent } \\ 5 & 30 & 100.00 & 30 & 100.00\end{array}$

Table 4.8. above displays the results of the opinion about the critical skills, knowledge and understanding acquired after the completion of the PHC trained professional nurses. 100\% strongly agreed that trained PHC professional nurses can assess, diagnose, treat and prescribe for the patients.

Table 4.9: Proper Screening

\begin{tabular}{|ccccc|}
\hline Q4 & Frequency & Percent & Cumulative Frequency & Cumulative Percent \\
$\mathbf{3}$ & 2 & 6.67 & 2 & 6.67 \\
$\mathbf{4}$ & 10 & 33.33 & 12 & 40.00 \\
$\mathbf{5}$ & 18 & 60.00 & 30 & 100.00 \\
\hline
\end{tabular}

Table 4.9.above displays the results of the opinion about the proper screening ascribed to the skills and knowledge of early diagnoses of diseases. $60 \%$ of respondents strongly agreed that PHC trained nurses can diagnose diseases early through proper screening. $33 \%$ of respondents agreed that the PHC trained nurses can diagnose diseases early through early screening. $6.67 \%$ of respondents neither agreed nor disagreed

Table 4.10: Referral System

\begin{tabular}{|ccccc|}
\hline Q5 & Frequency & Percent & Cumulative Frequency & Cumulative Percent \\
$\mathbf{4}$ & 5 & 16.67 & 5 & 16.67 \\
$\mathbf{5}$ & 25 & 83.33 & 30 & 100.00 \\
\hline & & \multicolumn{4}{c}{} \\
& & 217 & \\
\end{tabular}


The Table 4.10 above displays the results about the referral system. $83.33 \%$ of respondents strongly agreed that PHC training Learning Programme contribute hugely towards reducing the referral of patients to the hospitals. $16.67 \%$ agreed that PHC training contribute towards reducing the referral of patients to the hospitals. None of the respondents disagreed or strongly disagreed.

Table 4.11: Adherence to treatment protocols

\begin{tabular}{|ccccc|}
\hline Q6 & Frequency & Percent & Cumulative Frequency & Cumulative Percent \\
$\mathbf{4}$ & 15 & 50.00 & 15 & 50.00 \\
$\mathbf{5}$ & 15 & 50.00 & 30 & 100.00 \\
\hline
\end{tabular}

Table 4.11 above shows results about the adherence to treatment protocols. 50\% of the respondents strongly agreed that PHC Learning Programme ensure adherence to protocol. 50\% also agreed that PHC Learning Programme ensures that adherence to the protocol

\subsubsection{Administrative Competencies}

Table 4.12: Patient Waiting time for service

\begin{tabular}{|ccccc|}
\hline Q7 & Frequency & Percent & Cumulative Frequency & Cumulative Percent \\
$\mathbf{3}$ & 2 & 6.67 & 2 & 6.67 \\
$\mathbf{4}$ & 20 & 66.67 & 22 & 73.33 \\
$\mathbf{5}$ & 8 & 26.67 & 30 & 100.00 \\
\hline
\end{tabular}

Table 4.12 above reflects the results of PHC training programme contributing hugely in reducing the patient waiting time for the service in clinic and community health centre. $26.67 \%$ strongly agreed that PHC training programme contributes hugely in terms of reducing patients waiting time. $66.67 \%$ of respondents agreed that PHC training programme contributes a lot in terms of reducing patients waiting time in clinics and community health care. $6.67 \%$ of respondents neither agreed nor disagreed. None of the respondents strongly disagreed or disagreed.

Table 4.13: Comprehensive quality health care

\begin{tabular}{|ccccc|}
\hline Q8 & Frequency & Percent & Cumulative Frequency & Cumulative Percent \\
$\mathbf{4}$ & 17 & 56.67 & 17 & 56.67 \\
$\mathbf{5}$ & 13 & 43.33 & 30 & 100.00 \\
\hline
\end{tabular}

Table 4.13 shows results from the opinion about the PHC Learning Programme contributes hugely in rendering of comprehensive quality health care programmes. $56.67 \%$ of respondents agreed that PHC Learning Programme contributes hugely in rendering of the comprehensive quality health care. $43.33 \%$ strongly agreed that PHC Learning Programme contributes hugely in rendering of the comprehensive quality health care. None of the respondents strongly disagreed or disagreed.

Table 4.14: Administrative competency

\begin{tabular}{|ccccc|}
\hline Q9 & Frequency & Percent & Cumulative Frequency & Cumulative Percent \\
$\mathbf{4}$ & 10 & 33.33 & 10 & 33.33 \\
$\mathbf{5}$ & 20 & 66.67 & 30 & 100.00 \\
\hline
\end{tabular}

Table 4.14 above shows results of opinion about PHC Training Programme ability to equip professional nurses with facility management skills, report writing and monitoring. $66.67 \%$ of respondents strongly agreed that PHC Training Programme equipped professional nurses with administrative competency: facility management, report writing and monitoring. 33.33\% of respondents agreed that PHC Learning Programme equipped professional nurses with facility management skills, report writing and monitoring. None of the respondents disagreed or strongly disagreed. 
Table 4.15: Health education

\begin{tabular}{|ccccc|}
\hline Q10 & Frequency & Percent & Cumulative Frequency & Cumulative Percent \\
$\mathbf{3}$ & 4 & 13.33 & 4 & 13.33 \\
$\mathbf{4}$ & 6 & 20.00 & 10 & 33.33 \\
$\mathbf{5}$ & 20 & 66.67 & 30 & 100.00 \\
\hline
\end{tabular}

Table 4.15 above reflects the results of the opinion about the role played by the PHC Learning Programme in health promotion through health education. $66.67 \%$ of the respondents strongly agreed that PHC Learning Programme played a role in the prevention of the ill health, promotion of better health through primary health education.

\subsection{Overall Clinical and Administrative Competencies}

Table 4.5 indicates an overall percentage of $67 \%$ of the respondents strongly disagreed whereas $29.6 \%$ agreed to positive impact of PHC Learning Programme on health care delivery. Overall percentage of respondents neither agreed nor disagreed. None of respondents disagreed or strongly disagreed.

\subsubsection{Opinions From Open-Ended Questions}

As stated previously, respondents were asked a series of open-ended questions on their perceptions relating to the challenges in Primary Health Care Programme. The open-ended questions were asked and analysed textually by looking into common themes. The results are presented below.

Table 4.16: Additional Information from open-ended questions

\section{B.3 Additional Information Sought And Summary Of The Responses}

\begin{tabular}{|l|l|}
\hline $\begin{array}{l}\text { 11. What do you think are the challenges with the } \\
\text { primary health care learning programme }\end{array}$ & $\begin{array}{l}\bullet \text { Some of the mentors are not supportive during practical sessions. } \\
\text { - Some health programmes are not collaborative }\end{array}$ \\
\hline $\begin{array}{l}\text { 12. What do you think should be done to improve } \\
\text { the PHC learning programme? }\end{array}$ & $\begin{array}{l}\bullet \text { The PHC training must be standardised. } \\
\text { - Duration of the course must be extended to } 3 \text { years in terms of the duration }\end{array}$ \\
\hline
\end{tabular}

\subsubsection{Summary of Results}

The results of the study have been presented by simple frequency tables (proportions) for background variables and opinion related questions on the ratings by respondents on the effect of PHC Learning Programme in health care service delivery at Ehlanzeni District in Mpumalanga Province.

According to the demographics, the majority of the respondents were females which are accounted for the fact that most nurses are females. The age group was 30 years above and 50 years younger. There was higher percentage of respondents which were professional nurses. $50 \%$ of respondents had 5 to 10 years of job experience. Table 4.5 indicates an overall percentage of $67 \%$ of the respondents strongly disagreed whereas $29.6 \%$ agreed to positive impact of PHC Learning Programme on health care delivery. Overall percentage of respondents neither agreed nor disagreed. $0.00 \%$ of respondents disagreed or strongly disagreed.

In respect of significance of the PHC Learning Programme majority of respondents strongly agreed to the view that PHC Learning Programme enables professional nurses to acquire critical skills and clinical competencies in pursuit of quality and comprehensive health care. They further agreed to the opinion that professional nurses are also equipped with the administrative skills and competencies. None of the respondents disagreed or strongly disagreed about the opinion that Primary Health Care Learning Programme has a positive huge impact on health care service delivery.

\section{Discussion, Conclusion and Recommendations}

\subsection{Introduction}

This chapter discusses the key outcomes of the study. It also presents the conclusion from the study as well as recommendations for the future. 


\subsection{Demographics}

According to the demographic profiles, majority of respondents were females and this was anticipated since nursing profession is female dominated. Half of the respondents (50\%) were aged between 30 to 40 years. 30\% of respondents were aged 30 years and above. 20\% of respondents were aged between 41 and 50 years of age. Majority of respondents had 5 to 10 years of job experience.

Majority of respondents strongly agreed that through PHC Learning Programme professional nurses can assess, diagnose, treat and prescribe for patients and also strongly agreed that through PHC Learning Programme professional nurse can work independently without the supervision of doctors. Majority of respondents agreed that PHC Learning Programme contributes hugely towards reducing the referral of patients to hospitals and also agreed that PHC Learning Programme improves professional nurses' skills in facility management, report writing and monitoring.

\section{Conclusion}

The main finding of the study is that the Primary Health Care Learning Programme has a positive impact towards health care delivery hence trained professional nurses are imparted with clinical skills, knowledge and competencies which enable trained professional nurses to work independently and confidently without causing burden to the referral system. The study also reveals that the Primary Health Care Learning Programme plays a significance role in addressing the problem of shortage of full time doctors in Primary Health Care clinics through the provision of trained nurses who are able to assess, diagnose, treat and rehabilitate clients in the absence of medical doctors.

\section{Recommendations}

It is recommended that each facility should have PHC trained professional nurses to provide essential health care services hence the need to roll out such training to other nurses especially those already working in health facilities.

Thus, the PHC Learning programme must be treated as a priority and it must be included in nursing curriculum as a compulsory major subject at colleges or tertiary institutions.

\section{References}

ANON. 2001. The primary health care package for South Africa-A set of norms and standards. September 2001. 76Pp.

ANON. 2012.District Health Plan 2013/14, Ehlanzeni Health District, Mpumalanga Province, 199Pp.

Barron, P. 2011. The district health system: Progress to date health systems trust: Durban (online) Available at $<$ www.hst.co.za Accessed (8 January 2014)

Boon, AN.et al. 2006. Davidson's Principles \& Practice of Medicine.20TH Edition. Philadelphia, USA.

Burns, N. \& Grove, SK. 1993.The practice of Nursing Research-Conduct, Critique \& Utilization.2ND Edition. USA. http://www.hsag.co.za: Online. [01 July 2013]

Dieleman,M, M and Hammeijer, J.W. 2006. Improving health worker performance: in search of promising practice. WHO: Geneva Health Systems development: Primary Care. Available from: URL: http://www.worldbank.org/hsd

Leedy, P.D. and Ormrod, J.E. 2010. Practical Research Planning and Design. 9th edition. New Jersey: Peanson Merrill Prentice Hall

Magobe, NBD.et al.2010. 'Reasons for students' poor competencies in nursing, diagnosis treatment and care programme'. HealthSAGesondheid 15(1), Art.525: 6.

Monton, J, 1996, Understanding Social Research, Van Schaik, Pretoria.

National Department of Health. National core standards for health establishments in South Africa, Pretoria: National Department of Health, 2011.

National Department of Health. National Strategic Plan 2010/11-2012/13, Pretoria: National Department of Health, 2010.

SAS Institute. 2008. SAS User's Guide statistics 2008 edition, Cary, NC, SAS institute inc.

South Africa. Department of Health. 2000. The Primary Health Care Package for SA-Norms and Standards. Pretoria. URL: www.Department of Health.gov.za: Online. [08 January 2014].

South Africa Health Review. 2005. Health Systems Trust (online) available at <www.hst.co.za

South Africa. South African Council of Nurses. 1984. Are Nurses in South Africa Prescribing medicines judiciously? (Online). Pretoria: URL: www.sanc.co.za

South Africa 1997. White Paper on the Transformation of the Health System in South Africa. Department of Health

Whiteside, A. et al. 2003. What is driving the HIVIAIDS epidemic in Swaziland, and what more can we do about it? For Nercha, Heard \& Unaids. April 2003: 57.

World Health Organisation. Alma-Ata 1978: Primary Health care. Geneva: World Health Organisation; 1978

Who. 2009. Increasing access to health workers in remote and rural areas through improved retention. Geneva. (Online) available at <http: www.yale.edu/macmillan/apartheid/yachkistnasamyp2.pdf> . [29 November 2013] 